\title{
Protamine sulfate during transcatheter aortic valve implantation (PS TAVI) — a single-center, single-blind, randomized placebo-controlled trial
}

\author{
Karol Zbroński', Kajetan Grodecki', Roksana Gozdowska', Ewa Ostrowska', \\ Julia Wysińska', Bartosz Rymuza', Piotr Scisło', Radosław Wilimski², \\ Janusz Kochman', Krzysztof J Filipiak', Grzegorz Opolski', Zenon Huczek' \\ 1 1 st $^{\text {st }}$ Department of Cardiology, Medical University of Warsaw, Warszawa, Poland \\ ${ }^{2}$ Department of Cardiac Surgery, Medical University of Warsaw, Warszawa, Poland
}

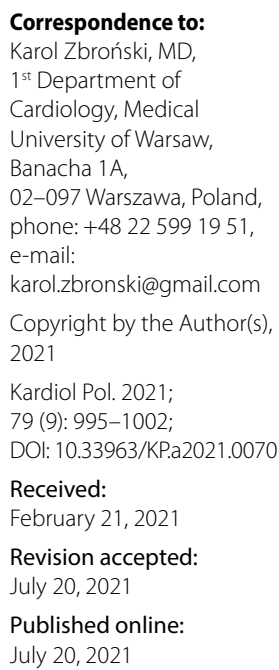

Correspondence to: Karol Zbroński, MD

$1^{\text {st }}$ Department of

Cardiology, Medical

University of Warsaw,

Banacha 1A,

02-097 Warszawa, Poland phone: +48225991951

e-mail:

karol.zbronski@gmail.com

Copyright by the Author(s), 2021

Kardiol Pol. 2021;

79 (9): 995-1002;

DOI: 10.33963/KP.a2021.0070

Received:

February 21, 2021

Revision accepted:

July 20, 2021

Published online:

July 20, 2021

\begin{abstract}
A B STR A C T
Background: Bleeding complications after transcatheter aortic valve implantation (TAVI) negatively affect the post-procedural prognosis. Routine use of protamine sulfate (PS) to reverse unfractionated heparin after TAVI was never assessed in a randomized controlled trial.
\end{abstract}

Aims: The aim of this study was to assess the impact of PS on bleeding complications after TAVI.

Methods: Between December 2016 and July 2020311 patients qualified to TAVI in one academic center were screened. Patients that met the inclusion criteria were randomized to either PS or normal saline administration at the moment of optimal valve deployment. Baseline, procedural, and follow-up data for up to 30 days were collected and analyzed. The primary endpoint (PE) was a composite of life-threatening and major bleeding according to Valve Academic Research Consortium within 48 hours after the procedure.

Results: Overall, 100 patients (48 males, median age 82 years) met the inclusion criteria and were included in the study. Forty-seven subjects (47\%) were randomized to PS. The primary endpoint occurred in $29 \%$ of the study population. Despite numerically lower rates of PE in patients randomized to PS, a statistical significance was not reached $(21 \%$ in the PS group and $36 \%$ in the placebo group; odds ratio $[\mathrm{OR}], 0.48 ; 95 \%$ confidence intervals $[\mathrm{Cl}] 0.2-1.2 ; P=0.11$ ). There were no significant differences in secondary endpoints.

Conclusions: Routine protamine sulfate administration did not significantly decrease the rate of major and life-threatening bleeding complications after TAVI. Larger studies are required to assess the impact of routine PS use.

Key words: aortic, implantation, protamine, sulfate, transcatheter, valve

Kardiol Pol 2021; 79, 9: 995-1002

\section{INTRODUCTION}

Transcatheter aortic valve implantation (TAVI) is an increasingly popular treatment method for patients with severe, symptomatic aortic stenosis (AS). In a plethora of studies either a clear benefit or non-inferiority was demonstrated in comparison to the gold standard - surgical aortic valve replacement - across almost all spectrums of AS patients [1]. Despite the fact, that many aspects of the antithrombotic treatment before and after TAVI have been studied, routine use of protamine sulfate (PS) to reverse the effect of the unfractionated heparin (UFH) was never included in those analyses.

Based on an expert consensus [2], UFH should be administered in every patient and should be reversed with PS after transapical and transfemoral TAVI except for transfemoral cases with minimal bleeding risk. The clinical practice, however, differs between centers [3,4]. The impact of PS on bleeding and thromboembolic complications is unknown and reports of the pro-thrombotic effect of the PS have been published in different clinical settings [5-7]. Hemor- 
WHAT'S NEW?

For the first time, the impact of routine administration of protamine sulfate (PS) in patients undergoing transcatheter aortic valve implantation was assessed in a randomized controlled trial (RCT). In this first, albeit a relatively small RCT, routine administration of PS did not significantly decrease the rate of major and life-threatening bleedings.

rhagic complications (at least major bleedings according to Valve Academic Research Consortium [VARC] criteria [8]) increase mortality after TAVI [9] and are relatively frequent ranging from $4.7 \%$ up to $77 \%$ [10-12]. No randomized trials assessing the influence of PS on bleeding rates after TAVI have been published to date. In order to comply with the rule of thumb - "when in doubt, randomize" - a clinical, placebo-controlled trial is required in order to properly assess the impact of protamine sulfate administration.

\section{METHODS}

\section{Trial design and funding}

The protamine sulfate during transcatheter aortic valve implantation (PS TAVI) is a single-center, single-blind randomized placebo-controlled trial in which routine PS administration to reverse UFH was compared to placebo. The study was investigator-initiated and did not receive any funding from the industry. Informed consent was obtained from all participating patients and the local ethics committee granted permission for the study (approval number KB/212/2016). The study protocol is available on ClinicalTrials.gov (NCT02974660). The study design is presented on Figure 1.

\section{Patients, randomization, and procedures}

The study aimed to include patients with severe, symptomatic aortic stenosis (aortic valve area $[A V A]<1.0 \mathrm{~cm}^{2}$ or indexed valve area less than $0.6 \mathrm{~cm}^{2} / \mathrm{m}^{2}$ or mean gradient $>40 \mathrm{~mm} \mathrm{Hg}$ or maximum jet velocity $>4.0 \mathrm{~m} / \mathrm{s}$ or velocity ratio $<0.25$ ), qualified by the Heart Team to a transfemoral TAVI with a planned application of pre-close devices such as Prostar or Proglide. The exclusion criteria were lack of informed consent, participation in another clinical trial, and known allergy to protamine sulfate.

Both mechanically- and self-expandable aortic valve prostheses of the second generation were used. In all cases, transfemoral access with at least two pre-close devices was applied. The procedures were performed in hybrid operating rooms under general anesthesia or local anesthesia with conscious sedation. After obtaining the vascular access, all patients received UFH at the dose of $100 \mathrm{IU} / \mathrm{kg}$ with the target activated clotting time (ACT) of 250-300 seconds.

At the moment of the optimal valve implantation, eligible patients were randomly assigned using the envelope method to either protamine sulfate or normal saline. The PS was administered in a slow bolus at the dose of $1 \mathrm{mg}$ per $100 \mathrm{IU}$ of unfractionated heparin administered within the last 30 minutes plus $0.5 \mathrm{mg}$ per $100 \mathrm{IU}$ of the UFH administered earlier. The successful reversal of heparin was confirmed by ACT measurements at baseline, after UFH boluses, before and after PS administration.

The type and number of preclose devices was noted as well as potential issues with the closure, including extravasation of the contrast in the final femoral angiography,

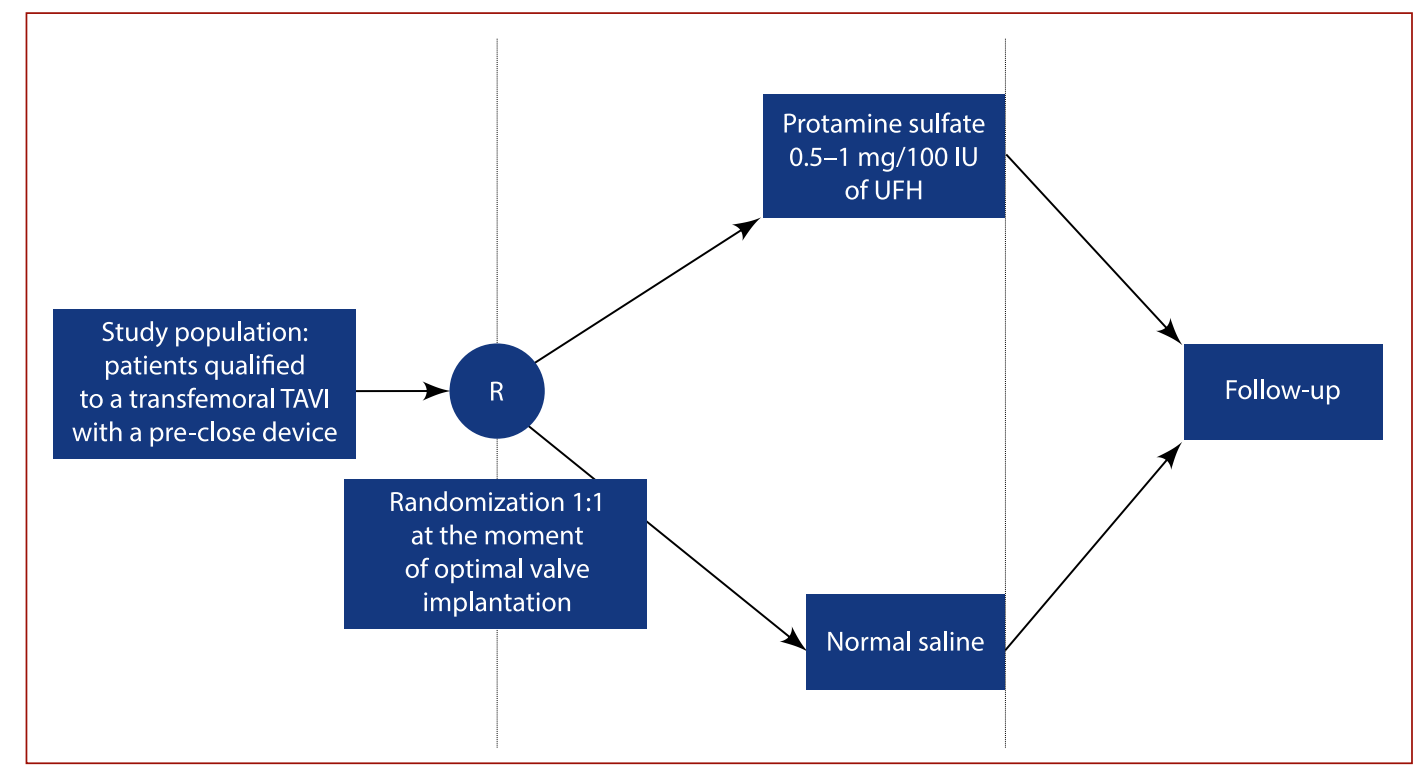

Figure 1. Study design

Abbreviation: TAVI, transcatheter aortic valve implantation; UFH, unfractionated heparin 
device malfunction, need for balloon angioplasty, stent implantation, or emergent surgical cut-down.

In terms of antithrombotic treatment before and after TAVI, patients without indications for chronic oral anticoagulation (OAC) were given loading doses of $300 \mathrm{mg}$ of aspirin and clopidogrel within 24 hours before TAVI, and then continued $75 \mathrm{mg}$ daily after the procedure. In patients requiring chronic OAC, the treatment was stopped 2-3 days before the procedure in order to obtain an international normalized ratio of $<2$ in case of vitamin $K$ antagonists (VKA) and 1-2 days before the procedure depending on the renal function in case of non-vitamin $\mathrm{K}$ antagonists. After TAVI the oral anticoagulation was restarted as soon as deemed safe, with additional bridging with low-molecular-weight heparin in patients receiving VKA.

\section{Endpoints and definitions}

The primary endpoint of the study was a composite of life-threatening and major bleeding complications according to VARC-2 at 48 hours after the procedure. The secondary endpoints were major and minor bleedings according to VARC-2 at 48 hours after the procedure, all-cause mortality at 30 days, a drop in hemoglobin concentration 48 hours after the procedure, the length of the hospitalization (the time from the index procedure to discharge), and thromboembolic events (stroke, transient ischemic attack, myocardial infraction) within 48 hours after the procedure. Coronary artery disease was defined as the presence of at least one lesion $>70 \%$ in the epicardial coronary vessel $>1.5 \mathrm{~mm}$ ( $>50 \%$ for left main), history of myocardial infarction, previous percutaneous coronary intervention, or coronary artery bypass grafting. Successful closure of the access artery was defined as obtaining proper hemostasis with no residual bleed, without device malfunction or a need for prolonged balloon inflation or covered stent implantation. Access-site and access-related vascular injury (ASARVI) was defined according to a modified classification by Sedaghat et al. [13]: type I, blush or minimal extravasation; type II, moderate extravasation $(<5 \mathrm{~mm})$; type III, major extravasation $(>5 \mathrm{~mm}$ ) including vessel perforation/rupture; and type IV, vessel dissection or occlusion.

\section{Statistical analysis}

Estimation was done based on the major and life-threatening bleeding rates from the historic material of the center $(28 \%)$, that 100 patients are required to have a $90 \%$ chance of detecting a significant decrease in the primary outcome occurrence from $28 \%$ in the placebo group to $5 \%$ in the PS group. The primary analysis was performed in the intention-to-treat population.

Continuous variables, expressed as the median and interquartile range (IQR), were compared between the study and control groups using Mann-Whitney U-test. Shapiro-Wilk test was used to confirm or reject the normal distribution of each continuous variable. Categorical variables, expressed as counts and percentages, were compared using the Chi-square test or Fisher's exact test, as appropriate.

A uni- and multivariable backward likelihood ratio logistic regression model was used to identify predictors of the primary and secondary endpoints. Variables from the univariate analysis (with a $P$ value of $\leq 0.20$ difference) were included in the multivariable analysis. Results are presented as odds ratio (OR) with $95 \%$ confidence intervals $(\mathrm{Cl})$.

All probability values reported are 2 -sided and a value $<0.05$ was considered to be significant. All data were processed using the SPSS software, version 22 (IBM SPSS Statistics, New York, NY, USA).

\section{RESULTS}

\section{Population}

Of the 311 consecutive patients screened between December 2016 and July 2020 in one academic center, 85 (27\%) underwent TAVI via an other-than-transfemoral or transfemoral with surgical cut-down access, 78 (25\%) participated in other clinical trials and $48(15 \%)$ did not consent to participation in the study. The study flow-chart is presented in Figure 2. Overall, one hundred patients were included in the study. The median age was 82 years (IQR $77-85$ ), there were 48 males (48\%), almost $90 \%$ of patients had hypertension, $43 \%$ - diabetes, and approximately one-third (36\%) was in New York Heart Association (NYHA) class III or IV. The median logistic EuroSCORE was 10.5 (IQR, 8-16). All the procedures were performed via transfemoral access and in all cases, a pre-close system was used. Detailed baseline data are shown in Table 1.

\section{Protamine sulfate administration}

Forty-seven subjects (47\%) were randomized to protamine sulfate and 56 patients $(56 \%)$ have received PS (cross-over: 9\%; in all cases the reason for cross-over was due to operators' decision). Median PS dose was $35 \mathrm{mg}$ or $0.5 \mathrm{mg}$ per $100 \mathrm{IU}$ of UFH. There were no major differences between the PS and placebo group, except for the presence of moderate or severe mitral regurgitation (49\% vs $30 \%$, PS and placebo respectively, $P=0.07$ ) as well as pre- and post-dilatation (pre-dilatation: PS $-45 \%$, placebo $-68 \%, P=0.03$; post-dilation: $P S-26 \%$, placebo $-46 \%, P=0.04)$.

\section{Primary endpoint}

The primary composite endpoint of VARC-defined major and life-threatening bleeding was observed in 29 patients (29\% of the study population, $21 \%$ of the PS cohort, and $36 \%$ of the control group, $P=0.13$ ). Major bleeding occurred in 19 patients $(19 \%, 13 \%$ of those randomized to PS, and $25 \%$ of the control group, $P=0.2)$. One disabling stroke $(1 \%)$ and 2 transient ischemic attacks (2\%) were reported. The 30-day all-cause mortality was $5 \%$. A detailed list of study endpoints is presented in Table 1. 


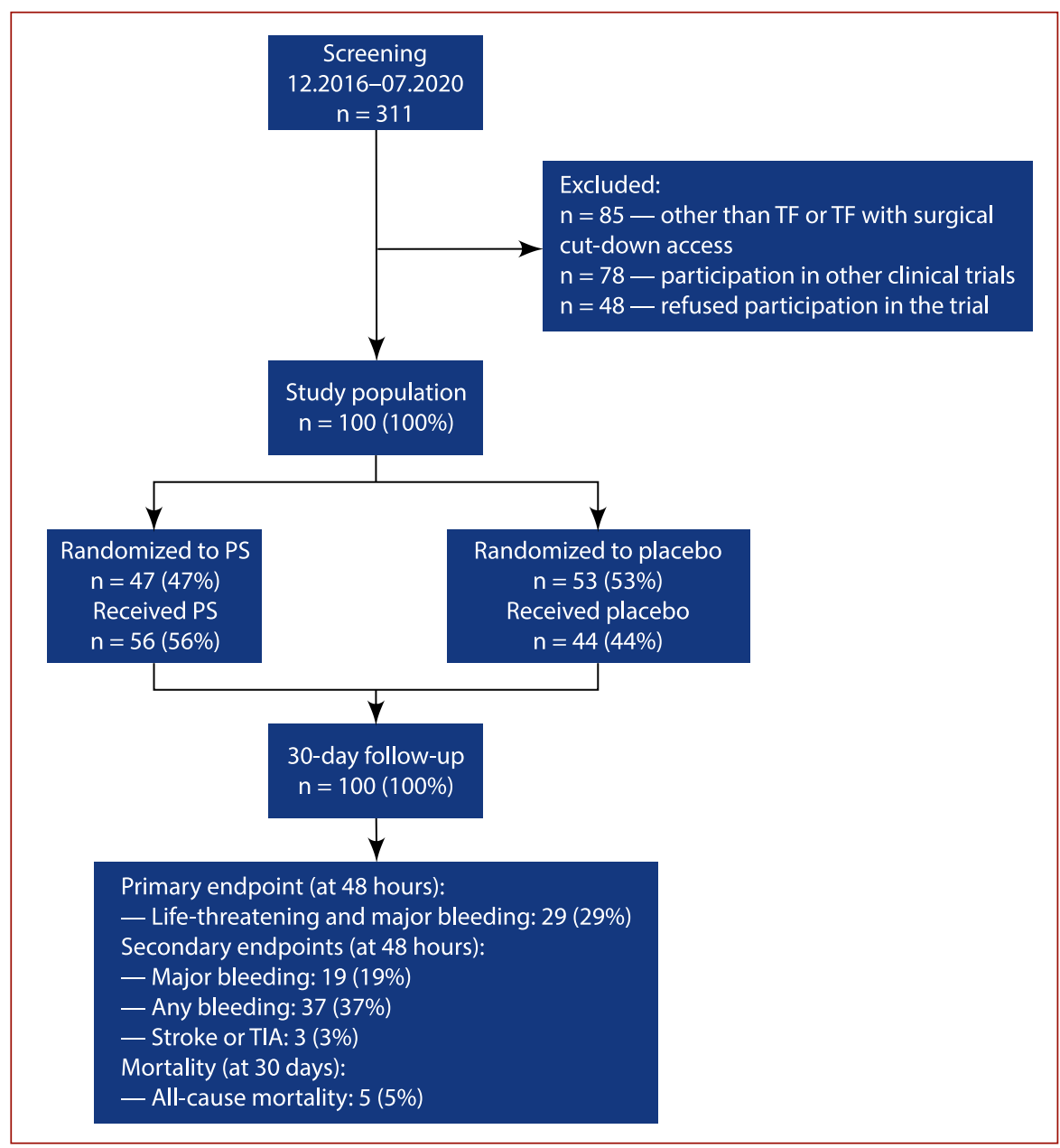

Figure 2. Study flowchart

Abbreviations: PS, protamine sulfate; TF, transfemoral; TIA, transient ischemic attack; other: see Figure 1

Table 1. Baseline and procedural characteristics of the study population along with endpoint rates

\begin{tabular}{|c|c|c|c|c|}
\hline & $\begin{array}{c}\text { Total } \\
(n=100)\end{array}$ & $\begin{array}{l}\text { Protamine sulfate } \\
\qquad(n=47,47 \%)\end{array}$ & $\begin{array}{c}\text { Placebo } \\
(n=53,53 \%)\end{array}$ & $P$-value \\
\hline \multicolumn{5}{|l|}{ Demographics } \\
\hline Female gender, $\mathrm{n}(\%)$ & $52(52)$ & $25(53)$ & $27(51)$ & 0.84 \\
\hline Age, years, median (IQR) & $81.7(77-85)$ & $81.8(77-85)$ & $81(75-86)$ & 0.63 \\
\hline \multicolumn{5}{|l|}{ Baseline characteristics } \\
\hline $\mathrm{BMI}, \mathrm{kg} / \mathrm{m}^{2}$, median (IQR) & $26.6(23-28)$ & $26(23-29)$ & $26.6(23-28)$ & 0.78 \\
\hline $\mathrm{BSA}, \mathrm{m}^{2}$, median (IQR) & $1.79(1.7-1.9)$ & $1.79(1.7-1.9)$ & $1.78(1.7-1.9)$ & 0.84 \\
\hline LogEuroSCORE, \%, median (IQR) & $10.5(7.9-16.3)$ & $10.5(7.8-16.3)$ & $10.4(8-16.9)$ & 0.75 \\
\hline Hypertension, n (\%) & $87(87)$ & $41(87)$ & $46(87)$ & 1 \\
\hline Diabetes, n (\%) & $43(43)$ & $24(51)$ & $19(36)$ & 0.16 \\
\hline $\mathrm{GFR}<30 \mathrm{ml} / \mathrm{min}, \mathrm{n}(\%)$ & $9(9)$ & $4(9)$ & $5(9)$ & 1 \\
\hline History of bleeding, $\mathrm{n}(\%)$ & $10(10)$ & $6(13)$ & $4(8)$ & 0.51 \\
\hline Coronary artery disease, $\mathrm{n}(\%)$ & $75(75)$ & $37(79)$ & $38(72)$ & 0.49 \\
\hline Prior cardiac surgery, $n(\%)$ & $12(12)$ & $7(15)$ & $5(9)$ & 0.54 \\
\hline History of stroke/TIA, n (\%) & $12(12)$ & $4(9)$ & $8(15)$ & 0.37 \\
\hline Atrial fibrillation, $\mathrm{n}(\%)$ & $44(44)$ & $20(43)$ & $24(45)$ & 0.84 \\
\hline COPD, n (\%) & $16(16)$ & $9(19)$ & $7(13)$ & 0.59 \\
\hline Prior pacemaker implantation, $\mathrm{n}(\%)$ & $24(24)$ & $8(17)$ & $16(30)$ & 0.16 \\
\hline Oral anticoagulation, $\mathrm{n}(\%)$ & $46(46)$ & $22(47)$ & $24(45)$ & 1 \\
\hline NYHA class 3-4, n (\%) & $36(36)$ & $16(34)$ & $20(38)$ & 0.84 \\
\hline LVEF, \%, median (IQR) & $58(53-63)$ & $60(55-64)$ & $58(53-62)$ & 0.4 \\
\hline LVEF <30\%, n (\%) & $10(10)$ & $6(13)$ & $4(8)$ & 0.51 \\
\hline Mean $\mathrm{AV}$ pressure gradient, $\mathrm{mm} \mathrm{Hg}$, median (IQR) & $42(34.5-50)$ & $42(38-50)$ & $42(34-50)$ & 0.81 \\
\hline Aortic valve area, $\mathrm{cm}^{2} / \mathrm{m}^{2}$, median (IQR) & $0.7(0.6-0.8)$ & $0.7(0.6-0.8)$ & $0.74(0.6-0.8)$ & 0.17 \\
\hline
\end{tabular}


Table 1. cont. Baseline and procedural characteristics of the study population along with endpoint rates

\begin{tabular}{|c|c|c|c|c|}
\hline & $\begin{array}{c}\text { Total } \\
(n=100)\end{array}$ & $\begin{array}{l}\text { Protamine sulfate } \\
\qquad(n=47,47 \%)\end{array}$ & $\begin{array}{c}\text { Placebo } \\
(n=53,53 \%)\end{array}$ & P-value \\
\hline Moderate or severe MR, n (\%) & $39(39)$ & $23(49)$ & $16(30)$ & 0.07 \\
\hline Serum creatinine, mg/dl, median (IQR) & $1.22(1-1.5)$ & $1.22(1.0-1.5)$ & $1.21(1-1.5)$ & 0.97 \\
\hline Hemoglobin, g/dL, median (IQR) & $12.5(11.4-13.6)$ & $12.6(11-13.6)$ & $12.4(11.5-13.6)$ & 0.9 \\
\hline \multicolumn{5}{|l|}{ Procedural and post-procedural data } \\
\hline General anaesthesia, n (\%) & $5(5)$ & $3(6)$ & $2(4)$ & 0.66 \\
\hline Other than femoral access, n (\%) & $0(0)$ & $0(0)$ & $0(0)$ & 1 \\
\hline Self-expandable prosthesis, $\mathrm{n}(\%)$ & $92(92)$ & $42(89)$ & $50(94)$ & 0.47 \\
\hline Delivery system profile > 16 French, $\mathrm{n}(\%)$ & $54(54)$ & $24(51)$ & $30(57)$ & 0.69 \\
\hline Predilation, n (\%) & $57(57)$ & $21(45)$ & $36(68)$ & 0.03 \\
\hline Postdilation, n (\%) & $36(36)$ & $12(26)$ & $24(46)$ & 0.04 \\
\hline Closure device, $\mathrm{n}(\%)$ & $100(100)$ & $47(100)$ & $53(100)$ & 1 \\
\hline Number of closure devices $>2, \mathrm{n}(\%)$ & $16(16)$ & $9(19)$ & $7(13)$ & 0.59 \\
\hline Successful closure, n (\%) & $91(91)$ & $43(92)$ & $48(91)$ & 1 \\
\hline ASARVI $\geq 3, \mathrm{n}(\%)$ & $6(6)$ & $3(6.4)$ & $3(5.7)$ & 1 \\
\hline Need for peripheral angioplasty, $\mathrm{n}(\%)$ & $15(15)$ & $7(15)$ & $8(15)$ & 1 \\
\hline UFH, IU $10^{3}$, median (IQR) & $7(6-8)$ & $7(6-8)$ & $7(6-8)$ & 0.83 \\
\hline UFH/kg, IU, median (IQR) & $100(86-117)$ & $100(87-117)$ & $100(86-117)$ & 0.9 \\
\hline LVEF, \%, median (IQR) & $60(52-65)$ & $60(55-65)$ & $57(51-62)$ & 0.17 \\
\hline Mean AV pressure gradient, $\mathrm{mm} \mathrm{Hg}$, median (IQR) & $8(6-10)$ & $8.5(5.8-11)$ & $8(6-10)$ & 0.72 \\
\hline Aortic valve area, $\mathrm{cm}^{2} / \mathrm{m}^{2}$, median (IQR) & $1.9(1.8-2.1)$ & $1.9(1.7-2)$ & $1.9(1.8-2.1)$ & 0.52 \\
\hline Serum creatinine, mg/dl, median (IQR) & $1.28(1-1.5)$ & $1.27(1-1.5)$ & $1.3(1-1.6)$ & 0.68 \\
\hline Hemoglobin, g/dL, median (IQR) & $9.8(8.8-10.9)$ & $9.8(8.8-11.1)$ & $9.8(8.8-10.8)$ & 0.83 \\
\hline \multicolumn{5}{|l|}{ Protamine sulfate } \\
\hline Randomized to protamine, $\mathrm{n}(\%)$ & $47(47)$ & - & - & - \\
\hline Received protamine, $\mathrm{n}(\%)$ & $56(56)$ & - & - & - \\
\hline Protamine dose, mg, median (IQR) & - & $35(25-50)$ & - & - \\
\hline Protamine dose per $100 \mathrm{IU}$ of UFH, mg, median (IQR) & - & $0.5(0.4-0.6)$ & - & - \\
\hline \multicolumn{5}{|l|}{ Endpoints } \\
\hline 30-day all-cause mortality, n (\%) & $5(5)$ & $3(6)$ & $2(4)$ & 0.66 \\
\hline Life threatening bleeding, n (\%) & $10(10)$ & $4(9)$ & $6(11)$ & 0.75 \\
\hline Major bleeding, n (\%) & $19(19)$ & $6(13)$ & $13(25)$ & 0.20 \\
\hline Minor bleeding, $\mathrm{n}(\%)$ & $8(8)$ & $4(9)$ & $4(8)$ & 1 \\
\hline Need for transfusion, $\mathrm{n}(\%)$ & $26(26)$ & $10(21)$ & $16(30)$ & 0.37 \\
\hline TIA, n (\%) & $2(2)$ & 0 & $2(4)$ & 0.5 \\
\hline Disabling stroke, n (\%) & $1(1)$ & $0(0)$ & $1(2)$ & 1 \\
\hline Need for permanent pacemaker, $\mathrm{n}(\%)$ & $24(24)$ & $11(23)$ & $13(25)$ & 1 \\
\hline Moderate or severe $\mathrm{PVL}, \mathrm{n}(\%)$ & $16(16)$ & $6(13)$ & $10(19)$ & 0.43 \\
\hline Length of stay, days, median (IQR) & $8(6-15)$ & $7(6-15)$ & $9(6-14.5)$ & 0.25 \\
\hline Any bleeding, $\mathrm{n}(\%)$ & $37(37)$ & $14(30)$ & $23(43)$ & 0.21 \\
\hline Major + life threatening bleeding , n (\%) & $29(29)$ & $10(21)$ & $19(36)$ & 0.13 \\
\hline Major + minor bleeding, $\mathrm{n}(\%)$ & $27(27)$ & $10(21)$ & $17(32)$ & 0.26 \\
\hline
\end{tabular}

Abbreviations: AR, aortic regurgitation; ASARVI, access-site or access-related vascular injury; AV, aortic valve; BMI, body mass index; $B S A$, body surface area; COPD, chronic obstructive pulmonary disease; GFR, glomerular filtration rate; IQR, interquartile range; LVEF, left ventricular ejection fraction; MR, mitral regurgitation; NYHA, New York Heart Association; PS, protamine sulfate; TIA, transient ischemic attack; UFH, unfractionated heparin

In a multivariable analysis of the primary endpoint occurrence, only serum creatinine (OR, $2.93 \mathrm{per} 1 \mathrm{mg} / \mathrm{dl}$ increment; $\mathrm{Cl}, 0.97-8.8 ; P=0.06$ ) has shown a trend towards statistical significance, while the remaining parameters included in the model: female gender $(\mathrm{OR}, 2.21 ; \mathrm{Cl}$, $0.86-5.66 ; P=0.1)$ and randomization to protamine sulfate administration $(\mathrm{OR}, 0.49 ; \mathrm{Cl} 0.92-1.2 ; P=0.13)$ did not reach significance (Table 2).

\section{Protamine sulfate and secondary endpoints and the per-protocol analysis}

The impact of randomization to PS on VARC-defined major bleeding (OR, 0.45; $\mathrm{Cl}, 0.2-1.3 ; P=0.14$, Table 3$)$, any bleed- ing (OR, 0.55; $\mathrm{Cl} 0.2-1.27 ; P=0.16)$ as well as the remaining study endpoints also did not reach statistical significance (Table 4). Results of the per-protocol analysis are presented in the Supplementary material, Tables S1, S2, and S3.

\section{DISCUSSION}

Despite the long-lasting presence of protamine sulfate in the pharmacological arsenal of peri-procedural drugs in the field of interventional cardiology, it has never been studied in a randomized fashion in the setting of TAVI. Both bleeding and thromboembolic complications may potentially arise from PS administration, with the first being a result of potential rebound anticoagulation due to PS short half-life 
Table 2. Uni- and multivariable logistic regression analysis of the composite of VARC-defined major and life-threatening bleeding occurrence

\begin{tabular}{|c|c|c|c|c|}
\hline & \multicolumn{2}{|c|}{ Univariate } & \multicolumn{2}{|c|}{ Multivariable } \\
\hline & OR (95\% Cl) & $P$-value & OR $(95 \% \mathrm{Cl})$ & $P$-value \\
\hline \multicolumn{5}{|l|}{ Demographics } \\
\hline Female gender & $1.78(0.74-4.31)$ & 0.2 & $2.21(0.86-5.66)$ & 0.1 \\
\hline Age per 1 year & $0.99(0.93-1.06)$ & 0.83 & & \\
\hline \multicolumn{5}{|l|}{ Baseline characteristics } \\
\hline BMl per $\mathrm{kg} / \mathrm{m}^{2}$ & $0.95(0.84-1.07)$ & 0.38 & & \\
\hline Hypertension & $1.42(0.36-5.59)$ & 0.62 & & \\
\hline Diabetes & $0.61(0.25-1.49)$ & 0.27 & & \\
\hline $\mathrm{GFR}<30 \mathrm{ml} / \mathrm{min}$ & $3.49(0.87-14.1)$ & 0.08 & $1.84(0.31-10.8)$ & 0.5 \\
\hline History of bleeding & $0.58(0.12-2.9)$ & 0.51 & & \\
\hline History of stroke/TIA & $0.8(0.2-3.17)$ & 0.75 & & \\
\hline Oral anticoagulation & $0.77(0.32-1.84)$ & 0.55 & & \\
\hline Serum creatinine per $1 \mathrm{mg} / \mathrm{dl}$ & $2.35(0.89-6.21)$ & 0.09 & $2.93(0.97-8.79)$ & 0.06 \\
\hline Hemoglobin per $1 \mathrm{~g} / \mathrm{dl}$ & $1.1(0.86-1.4)$ & 0.45 & & \\
\hline \multicolumn{5}{|l|}{ Procedural data } \\
\hline General anaesthesia & $1.68(0.27-10.6)$ & 0.58 & & \\
\hline Delivery system profile $>16$ French & $0.88(0.37-2.09)$ & 0.77 & & \\
\hline Number of closure devices $>2$ & $2.19(0.73-6.59)$ & 0.16 & $2.27(0.68-7.5)$ & 0.18 \\
\hline Successful closure & $0.47(0.12-1.91)$ & 0.29 & & \\
\hline ASARVI $\geq 3$ & $2.62(0.5-13.8)$ & 0.26 & & \\
\hline Need for peripheral angioplasty & $0.87(0.25-3)$ & 0.83 & & \\
\hline UFH/kg per $1 \mathrm{IU}$ & $1(0.99-1.02)$ & 0.77 & & \\
\hline Randomized to protamine & $0.48(0.2-1.19)$ & 0.11 & $0.49(0.92-1.2)$ & 0.13 \\
\hline Received protamine & $0.64(0.27-1.54)$ & 0.32 & & \\
\hline
\end{tabular}

Abbreviations: $\mathrm{Cl}$, confidence intervals; $\mathrm{OR}$, odds ratio; other — see Table 1

Table 3. Uni- and multivariable logistic regression analysis of VARC-defined major bleeding occurrence

\begin{tabular}{|c|c|c|c|c|}
\hline & \multicolumn{2}{|c|}{ Univariate } & \multicolumn{2}{|c|}{ Multivariable } \\
\hline & OR $(95 \% \mathrm{Cl})$ & $P$-value & OR $(95 \% \mathrm{CI})$ & $P$-value \\
\hline \multicolumn{5}{|l|}{ Demographics } \\
\hline Female gender & $1.76(0.63-4.92)$ & 0.28 & $1.77(0.51-5.14)$ & 0.29 \\
\hline Age per 1 year & $2(0.9-1.1)$ & 0.82 & & \\
\hline \multicolumn{5}{|l|}{ Baseline characteristics } \\
\hline BMI per $\mathrm{kg} / \mathrm{m}^{2}$ & $1.01(0.9-1.1)$ & 0.92 & & \\
\hline Hypertension & $0.75(0.2-3)$ & 0.69 & & \\
\hline Diabetes & $0.73(0.26-2)$ & 0.55 & & \\
\hline $\mathrm{GFR}<30 \mathrm{ml} / \mathrm{min}$ & $2.3(0.5-10.4)$ & 0.26 & $2.6(0.57-12)$ & 0.22 \\
\hline \multicolumn{5}{|l|}{ History of bleeding } \\
\hline \multicolumn{5}{|l|}{ History of stroke/TIA } \\
\hline Oral anticoagulation & $1.1(0.4-2.9)$ & 0.89 & & \\
\hline Serum creatinine per $1 \mathrm{mg} / \mathrm{dl}$ & $1.5(0.6-4)$ & 0.39 & & \\
\hline Hemoglobin per $1 \mathrm{~g} / \mathrm{dl}$ & $1.02(0.8-1.4)$ & 0.87 & & \\
\hline \multicolumn{5}{|l|}{ Procedural data } \\
\hline General anaesthesia & $3.1(0.5-19.8)$ & 0.24 & $3.6(0.53-24.5)$ & 0.19 \\
\hline Delivery system profile $>16$ French & $0.55(0.2-1.5)$ & 0.31 & & \\
\hline Number of closure devices $>2$ & $1.5(0.4-5.4)$ & 0.51 & & \\
\hline Successful closure & $0.8(0.2-4.2)$ & 0.8 & & \\
\hline ASARVI $\geq 3$ & $0.84(0.1-7.7)$ & 0.88 & & \\
\hline Need for peripheral angioplasty & $0.62(0.1-3)$ & 0.55 & & \\
\hline UFH/kg per $1 \mathrm{IU}$ & $1.01(0.99-1.03)$ & 0.58 & & \\
\hline Randomized to protamine & $0.45(0.2-1.3)$ & 0.14 & $0.45(0.16-1.3)$ & 0.14 \\
\hline Received protamine & $0.5(0.2-1.4)$ & 0.18 & & \\
\hline
\end{tabular}

Abbreviations: see Table 1 and 2 
Table 4. Impact of protamine sulfate administration on study endpoints occurrence

\begin{tabular}{l|c|c} 
& OR (95\% CI) & P-value \\
\hline 30-day all-cause mortality, $\mathrm{n}(\%)$ & $1.8(0.3-10.8)$ & 0.55 \\
Life threatening bleeding, $\mathrm{n}(\%)^{\mathrm{a}}$ & $0.73(0.2-2.76)$ & 0.64 \\
Major bleeding, $\mathrm{n}(\%)^{\mathrm{a}}$ & $0.45(0.2-1.3)$ & 0.14 \\
Minor bleeding, $\mathrm{n}(\%)^{\mathrm{a}}$ & $1.14(0.3-4.8)$ & 0.86 \\
Need for transfusion, $\mathrm{n}(\%)^{\mathrm{a}}$ & $0.63(0.3-1.56)$ & 0.31 \\
$\mathrm{TIA}, \mathrm{n}(\%)^{\mathrm{a}}$ & - & - \\
Disabling stroke, $\mathrm{n}(\%)^{\mathrm{a}}$ & - & - \\
Any bleeding, $\mathrm{n}(\%)^{\mathrm{a}}$ & $0.55(0.2-1.27)$ & 0.16 \\
Major + life threatening bleeding, & $0.48(0.2-1.19)$ & 0.11 \\
$\mathrm{n}(\%)^{\mathrm{a}}$ & & \\
Major + minor bleeding, $\mathrm{n}(\%)^{\mathrm{a}}$ & $0.57(0.2-1.42)$ & 0.23 \\
\hline
\end{tabular}

at 48 hours.

Abbreviations: see Table 1 and 2

(7 minutes as compared to UFH's 60-90 minutes), while the latter occurring due to possible rebound thrombosis after sudden UFH reversal [14]. In a study assessing UFH reversal with PS after carotid endarterectomy, a trend towards thrombosis and stroke was reported [5].

To the best of our knowledge, our study reports the results of the first-ever randomized, clinical, placebo-controlled trial evaluating the impact of routine PS administration after TAVI. The trial design aimed to assess the impact of PS in the setting reflecting the majority of TAVI procedures performed worldwide - via transfemoral access with a pre-close device.

Despite a numerically lower rate of VARC-defined life-threatening and major hemorrhagic complications in patients randomized to protamine sulfate, the bleeding reduction did not reach statistical significance. Similarly, there were no differences in terms of stroke or transient ischemic attack (TIA) occurrence between the PS and the placebo group, however, the number of thromboembolic events was low in the study population.

Only 2 published papers focused on protamine sulfate administration after TAVI. In a recently published retrospective analysis of our own material (186 patients undergoing transfemoral TAVI, 44\% via surgical cut-down, $21 \%$ received $P S$ at operators' discretion) PS administration did not decrease the rate of bleeding complications [15]. Conversely, in a much larger (873 patients), single-center, prospective observational study, in which 677 patients undergoing TAVI received PS, protamine administration resulted in significantly lower rates of life-threatening and major bleeding complications while not increasing the occurrence of stroke and myocardial infarction [16]. That? study, however, was not randomized and the use of PS was left at operators' discretion in the initial phase of the study, whereas towards the end of the trial all patients received protamine, potentially introducing a selection bias as well as a confounding bias secondary to improvements in vascular access technics over time.

The reported rate of VARC-defined life-threatening and major bleeding complications (29\%) remains high but is in line with the previously published results from large real-life populations of TAVI patients $[4,14,17]$ - in a meta-analysis of 3519 patients, the rate of hemorrhagic sequelae ranged from $27 \%$ to $77 \%$ [12]. The tendency to suffer from bleeding complications is multifactorial in this elderly, often frail population with numerous comorbidities. Apart from obvious bleeding risks associated with the primary and secondary access sites, such as the diameter of the femoral and iliac arteries, the delivery sheath profile, and the quality of the puncture and the closure, additional blood loss may arise either from gastrointestinal and urinary tracts [12] or from acquired coagulopathies, such as acquired von Willebrand syndrome and heparin-induced thrombocytopenia [18]. The disproportionate rate of bleeding complications and ASARVI can potentially be explained by a blood loss occurring throughout the procedure, despite a successful hemostasis visualized during final angiography of the femoral access.

In terms of primary endpoint predictors, only a negative impact of serum creatinine was close to reaching statistical significance. Renal function-dependent increase in bleeding complications after TAVI is consistent with previous reports and may be a result of impaired metabolism of a variety of antithrombotic drugs administered before, during, and after TAVI. In a study in which ACT-guided heparin administration was assessed in 362 patients, baseline GFR was an independent predictor of 30-day bleeding with an odds ratio of 0.96 [19].

Lack of statistical significance precludes drawing unequivocal conclusions in regard to the usefulness of routine PS administration after TAVI. Perhaps, a larger, multi-center trial would provide a clear answer to whether the rich historical past of protamine sulfate can translate to a great future in the TAVI world.

\section{Limitations}

Despite the obvious advantages of the randomized placebo-controlled trial, our study has a number of limitations. First and most importantly, the small sample size precluded obtaining statistically significant differences between the groups. Secondly, the cross-over rate was almost $9 \%$, and concerned patients randomized to placebo, who ended up receiving protamine. Thirdly, the endpoints were not independently adjudicated and the intervention was not blinded. On the other hand, only patients qualified for a transfemoral procedure with a pre-close device were included. This eliminated the potential bias of surgeon-dependent hemostasis present in cut-down approaches.

\section{CONCLUSIONS}

Routine protamine sulfate administration did not significantly decrease the rate of major and life-threatening bleeding complications after TAVI. Larger studies are required to assess the impact of routine PS use. 


\section{Supplementary material}

Supplementary material is available at https://journals. viamedica.pl/kardiologia_polska.

\section{Article information}

Conflict of interest: None declared.

Trial registry and number: ClinicalTrials.gov; NCT02974660.

Open access: This article is available in open access under Creative Common Attribution-Non-Commercial-No Derivatives 4.0 International (CC BY-NC-ND 4.0) license, allowing to download articles and share them with others as long as they credit the authors and the publisher, but without permission to change them in any way or use them commercially. For commercial use, please contact the journal office at kardiologiapolska@ptkardio.pl.

How to cite: Zbroński K, Grodecki, K, Gozdowska R, et al. Protamine sulfate during transcatheter aortic valve implantation (PSTAVI) - a single-center, single-blind, randomized placebo-controlled trial. Kardiol Pol. 2021; 79(9): 995-1002, doi: 10.33963/KP.a2021.0070.

\section{REFERENCES}

1. Mack MJ, Leon MB, Thourani VH, et al. PARTNER 3 Investigators. Transcatheter aortic-valve replacement with a balloon-expandable valve in low-risk patients. N Engl J Med. 2019; 380(18): 1695-1705, doi: 10.1056/NEJMoa1814052, indexed in Pubmed: 30883058.

2. Holmes DR, MackMJ, Kaul S, et al. 2012 ACCF/AATS/SCAI/STS expert consensus document on transcatheter aortic valve replacement: developed in collabration with the American Heart Association, American Society of Echocardiography, European Association for Cardio-Thoracic Surgery, Heart Failure Society of America, Mended Hearts, Society of Cardiovascular Anesthesiologists, Society of Cardiovascular Computed Tomography, and Society for Cardiovascular Magnetic Resonance. JThorac Cardiovasc Surg. 2012; 144: e29-e84, doi: 10.1016/j.jtcvs.2012.03.001.

3. Gauthier $C$, Astarci $P$, Baele $P$, et al. Mid-term survival after transcatheter aortic valve implantation: Results with respect to the anesthetic management and to the access route (transfemoral versus transapical). Ann Card Anaesth. 2015; 18(3): 343-351, doi: 10.4103/0971-9784.159804, indexed in Pubmed: 26139739.

4. Borz B, Durand E, Godin M, et al. Incidence, predictors and impact of bleeding after transcatheter aortic valve implantation using the balloon-expandable Edwards prosthesis. Heart. 2013; 99(12): 860-865, doi: 10.1136/heartjnl-2012-303095, indexed in Pubmed: 23236027.

5. Fearn SJ, Parry AD, Picton AJ, et al. Should heparin be reversed after carotid endarterectomy? A randomised prospective trial. Eur J Vasc Endovasc Surg. 1997; 13(4):394-397, doi: 10.1016/s1078-5884(97)80082-2, indexed in Pubmed: 9133992.

6. Levison JA, Faust GR, Halpern VJ, et al. Relationship of protamine dosing with postoperative complications of carotid endarterectomy. Ann Vasc Surg. 1999; 13(1): 67-72, doi: 10.1007/s100169900222, indexed in Pubmed: 9878659.

7. Cosgrave J, Qasim A, Latib A, et al. Protamine usage following implantation of drug-eluting stents: a word of caution. Catheter Cardiovasc Interv. 2008; 71(7): 913-914, doi: 10.1002/ccd.21439, indexed in Pubmed: 18383161.
8. Kappetein AP, Head SJ, Genereux P, et al. Updated standardized endpoint definitions for transcatheter aortic valve implantation: the Valve Academic Research Consortium-2 consensus document (VARC-2). Eur J Cardiothorac Surg. 2012; 42(5): S45-S60, doi: 10.1093/ejcts/ezs533.

9. Rodés-Cabau J, Dauerman HL, Cohen MG, et al. Antithrombotic treatment in transcatheter aortic valve implantation: insights for cerebrovascular and bleeding events. J Am Coll Cardiol. 2013;62(25):2349-2359, doi: 10.1016/j. jacc.2013.03.029, indexed in Pubmed: 23583252.

10. Gerckens U, Tamburino C, Bleiziffer S, et al. Final 5-year clinical and echocardiographic results for treatment of severe aortic stenosis with a self-expanding bioprosthesis from the ADVANCE Study. Eur Heart J. 2017; 38(36): 2729-2738, doi: 10.1093/eurheartj/ehx295, indexed in Pubmed: 28633375.

11. Meredith IT. Australia-New Zealand corevalve transcatheter aortic valve study. Paper presented at: transcatheter valve therapies: an advanced scientific and clinical workshop. Seattle, Washington, June 2-5, 2012.

12. Généreux $P$, Head $S$, Mieghem NV, et al. Clinical outcomes after transcatheter aortic valve replacement using valve academic research consortium definitions. J Am Coll Cardiol. 2012; 59(25): 2317-2326, doi: 10.1016/j. jacc.2012.02.022

13. Sedaghat A, Neumann N, Schahab N, et al. Routine endovascular treatment with a stent graft for access-site and access-related vascular injury in transfemoral transcatheter aortic valve implantation. Circ Cardiovasc Interv. 2016; 9(8): e003834, doi: 10.1161/CIRCINTERVENTIONS.116.003834, indexed in Pubmed: 27512089.

14. Sergie Z, Lefèvre $T$, Van Belle $E$, et al. Current periprocedural anticoagulation in transcatheter aortic valve replacement: could bivalirudin be an option? Rationale and design of the BRAVO 2/3 studies. J Thromb Thrombolysis. 2013; 35(4): 483-493, doi: 10.1007/s11239-013-0890-3, indexed in Pubmed: 23553245

15. Zbroński K, Grodecki K, Gozdowska R, et al. Use of protamine sulfate during transfemoral transcatheter aortic valve implantation - a preliminary assessment of administration rate and impact on complications. Postepy Kardiol Interwencyjnej. 2020; 16(3): 306-314, doi: 10.5114/aic.2020.99266, indexed in Pubmed: 33597996.

16. Al-Kassou B, Kandt J, Lohde L, et al. Safety and efficacy of protamine administration for prevention of bleeding complications in patients undergoing TAVR. JACC Cardiovasc Interv. 2020; 13(12): 1471-1480, doi: 10.1016/j.jcin.2020.03.041, indexed in Pubmed: 32553337.

17. Stortecky S, Stefanini GG, Pilgrim T, et al. Validation of the valve academic research consortium bleeding definition in patients with severe aortic stenosis undergoing transcatheter aortic valve implantation. J Am Heart Assoc. 2015; 4(10): e002135, doi: 10.1161/JAHA.115.002135, indexed in Pubmed: 26408014.

18. Grodecki K, Zbroński K, Przybyszewska-Kazulak E, et al. Pre-procedural abnormal function of von Willebrand Factor is predictive of bleeding after surgical but not transcatheter aortic valve replacement. J Thromb Thrombolysis. 2019; 48(4): 610-618, doi: 10.1007/s11239-019-01917-7, indexed in Pubmed: 31359325.

19. Bernelli $C$, Chieffo $A$, Montorfano $M$, et al. Usefulness of baseline activated clotting time-guided heparin administration in reducing bleeding events during transfemoral transcatheter aortic valve implantation. JACC Cardiovasc Interv. 2014; 7(2): 140-151, doi: 10.1016/j.jcin.2013.10.016, indexed in Pubmed: 24556092. 